\title{
Retrato sem parede: o Bom Crioulo, de Adolfo Caminha
}

\author{
Regina Dalcastagnè ${ }^{1}$
}

Com o passar do tempo, obras que surpreenderam pela originalidade costumam perder seu impacto, seja porque suas conquistas técnicas ou suas escolhas repertoriais já foram incorporadas e reinterpretadas pelos produtores literários, seja porque a surpresa do diferente costuma se esvaziar após sua própria execução. ${ }^{2}$ Não é o caso de Bom Crioulo, de Adolfo Caminha. Lançado em 1895, para o escândalo da sociedade da época, ele continua, de algum modo, sendo uma perturbação em nosso cenário cultural. Reivindicado atualmente como o primeiro romance brasileiro a trazer a público um protagonista homossexual, Bom Crioulo chama atenção ainda para uma série de outras ausências em nossa literatura - não apenas a do século xıx, mas também a de hoje, que, de um modo geral, não dá guarida para personagens como Amaro.

Afinal, além de gay, ele é negro e trabalhador braçal. Juntam-se aí três características que, isoladas, já seriam suficientes para torná-lo invisível nos discursos predominantes que circulam pelos mais variados espaços sociais. No discurso literário, uma personagem com essas marcas de classe, raça e orientação sexual poderia até compor o pano de fundo de alguma narrativa, como representante de uma "diversidade" que é necessário reconhecer. De resto, o centro da cena, lá onde as coisas acontecem de fato, ainda hoje permanece ocupado por homens e mulheres brancos, heterossexuais, de classe média ou da elite econômica, vinculados ao universo intelectual. Nos romances brasileiros contemporâneos, em especial aqueles publicados pelas editoras mais prestigiadas e que obtêm maior impacto entre o público e a crítica, são raros os protagonistas negros, raros os protagonistas homossexuais, raros os protagonistas trabalhadores (DAlCAstagnè, 2012). Por isso mesmo, o estranhamento que o leitor sente ao ler o livro permanece, mais de cem anos depois dele ter sido escrito.

1 Doutora, professora titular de literatura brasileira da Universidade de Brasília (UNB), Brasília, Distrito Federal, Brasil. E-mail: rdal@unb.br

2 A versão inicial deste texto foi apresentada originalmente no X Seminário Internacional de História da Literatura, realizado em Porto Alegre, e foi publicada em seus anais. 
Temos aí o indicador de um problema social - em que a experiência de vida de alguns grupos é considerada menos valiosa e, consequentemente, excluída dos espaços de construção do discurso -, mas também um tipo de empobrecimento estético. Ao interromper suas atividades e abrir um romance, o leitor busca, de alguma maneira, se conectar a outras existências. Pode querer encontrar ali alguém como ele, em situações que viverá um dia ou que espera jamais viver. Mas pode ainda querer entender o que é ser o outro, morar em terras longínquas, falar uma língua estranha, ter outro sexo, outra cor, outras tradições, um modo diferente de enxergar o mundo. $\mathrm{O}$ romance, enquanto gênero, promete tudo isso a seus leitores - que podem ser leitoras, que têm cores, idades, crenças, instrução, contas bancárias, perspectivas de vida muito diferentes entre si.

Reconhecer-se em uma representação artística, ou reconhecer o outro dentro dela, faz parte de um processo de legitimação de identidades, ainda que elas sejam múltiplas. Daí a necessidade da inserção de diferentes perspectivas sociais nessas construções. De acordo com a definição de Iris Marion Young (20oo, p. 136), o conceito de "perspectiva social" reflete o fato de que "pessoas posicionadas diferentemente [na sociedade] possuem experiência, história e conhecimento social diferentes, derivados desta posição". Vividas de forma menos ou mais consciente, as perspectivas sociais são o reflexo, nas maneiras de ver e entender o que as cerca, da pluralidade de condições em que as pessoas se encontram no mundo.

Assim, mulheres e homens, trabalhadores e patrões, velhos e moços, negros e brancos, moradores do campo e da cidade, homossexuais e heterossexuais, umbandistas e católicos vão ver e expressar o mundo de diferentes formas. A incorporação disso na literatura implica, necessariamente, na elaboração de novos modos de dizer - outros espaços precisam ser descritos, outros tempos articulados, outras linguagens devem ocupar o texto. Com isso, novos estilos têm de ser elaborados, às vezes até com a fusão de diferentes gêneros - como a absorção da estrutura do rap nos contos de um escritor contemporâneo como Ferréz (2006) para falar da vida em uma favela, por exemplo. Isso significa enriquecimento estético para a literatura. No caso de Bom Crioulo, um escravo fugido que embarca sonhando viver em liberdade no mar - uma das poucas opções possíveis à época - impõe toda uma outra perspectiva à narrativa. 
Não é através do olhar de senhores do Cosme Velho, nem de garotos atormentados em internatos, sequer com os oficiais dos navios que vamos seguir essa história, mas sim a partir dos trabalhadores do convés. Nós os acompanhamos enquanto esfregam o chão, carregam as sacas, erguem as velas, enquanto recebem chibatadas ou mesmo ao cair da noite, quando cantam à luz da lua. Há, é claro, um narrador que se interpõe entre esses homens e nós um narrador branco, heterossexual, intelectual e de classe média -, que seleciona o que vai nos contar, que avalia e julga, com os valores e os preconceitos de seu tempo. Mesmo que involuntariamente, este narrador ajuda a situar o universo social em que suas personagens se movem: um universo em que tais preconceitos são dominantes, estabelecem expectativas e cerceiam possibilidades. Nós, leitores de hoje, temos uma vantagem. Os mesmos preconceitos certamente permanecem, mas tendem a se expressar numa outra linguagem. Assim, o que passava batido para o leitor contemporâneo de Caminha, causa estranheza aos nossos olhos e marca a posição de exterioridade do narrador em relação ao objeto de sua escrita.

Ao mesmo tempo, ao descrever esses trabalhadores, a narrativa acaba por torná-los presentes e, assim, permite que façamos uma interpretação alternativa dos fatos. É por isso que podemos dizer que a democratização da literatura passa pela ampliação da pluralidade tanto dos criadores quanto das experiências de vida que são consideradas dignas de reconstrução em prosa ou poesia.

Bom Crioulo recebe esse nome porque aos 18 anos, grande e perigosamente forte, trabalha com prazer e se dá com todo mundo, feliz na liberdade recém-conquistada, que "entrava-lhe pelos olhos, pelos ouvidos, pelas narinas, por todos os poros" (p. 39). ${ }^{3}$ Até que um dia tudo começa a desandar - uns acham que é por causa da cachaça, outros insinuam que ele perdera o interesse no trabalho desde que conhecera Aleixo, o grumete de olhos azuis que vai enlouquecê-lo. No entanto, antes de nos concentrarmos nessas insinuações, é preciso voltar atrás. Entre um momento e outro, o narrador já havia nos dado, em um curto parágrafo, outra versão da história, com a perspectiva de Amaro:

Contava então cerca de trinta anos e trazia a gola de marinheiro de segunda-classe. Por sua vontade não sairia mais barra fora: em dez anos viajara quase o mundo inteiro, arriscando a vida cinquenta vezes, sacrificando-

3 As referências do romance serão indicadas, ao longo do texto, pelo número da página. Todas as citações são retiradas da edição da Hedra, conforme referências ao final do artigo. 
se inutilmente. Afinal a gente aborrece... Um pobre marinheiro trabalha como besta, de sol a sol, passa noites acordado, atura desaforo de todo mundo, sem proveito, sem o menor proveito! O verdadeiro é levar a vida 'na flauta' (p. 45).

Ou seja, o que um resumo breve do livro pode dar a entender esconde o transcurso de dez anos de trabalho árduo e sem compensações. Não havia bebida nem paixão proibida que pudesse fazer o que só a experiência forneceria a Amaro: ao se transformar em um homem livre e maduro, ele percebe que o trabalho assalariado pode se tornar uma nova escravidão. É decepção que vemos aí. Não teríamos como chegar a essa conclusão se o narrador houvesse subtraído a informação anterior, o ponto de vista de um homem que se quer dono de seu destino. Da mesma forma, o narrador descreve o desejo crescente de Amaro por Aleixo e os seus subterfúgios para conquistar o garoto (que envolvem cuidados, conselhos e longas conversas sobre a cidade do Rio de Janeiro) de modo quase objetivo. Chega a mostrá-los se aproximando para o sexo e então interrompe tudo, fecha a cena e o capítulo decretando: "E consumou-se o delito contra a natureza" (p. 63).

A frase, isolada no texto, explicita a necessidade social da condenação do ato homossexual, mas não nos impede, mais uma vez, de entender as motivações das personagens, tanto as de Amaro, perdidamente apaixonado pela primeira vez na vida, quanto as de Aleixo, que o estima também, por sua força e, especialmente, por sua lealdade. Há, portanto, uma discrepância entre o que o narrador sentencia e aquilo que ele mostra. Ou seja, temos um narrador que se divide entre o respeito aos valores morais e às crenças, inclusive "científicas", de sua época e o empenho em descrever o que percebe ser uma outra perspectiva de vida, que terá, é claro, um desfecho trágico.

$O$ fato de Amaro ser negro não lhe traz maiores dificuldades dentro do navio: "Ali não se olhava a cor ou a raça do marinheiro: todos eram iguais, tinham as mesmas regalias - o mesmo serviço, a mesma folga” (p. 40). Uma idealização, decerto, pois mesmo quando há camaradagem e apoio mútuo, é difícil que um espaço social permaneça inteiramente imune ao racismo que atravessa e contamina toda a sociedade à sua volta. E se o trabalho duro dos marinheiros pode, em certa medida, irmanar negros e brancos, não há como ignorar o fato de que todos os oficiais são brancos e, assim, a hierarquia militar reflete também a hierarquia racial vigente na época. 
Mas, nos termos da narrativa, o problema estava do lado de fora da embarcação e, evidentemente, do lado de fora do livro. Mais do que preconceito, havia medo ali. A história se passa um pouco antes da abolição da escravatura, não muito distante, portanto, da data de sua publicação: "Nesse tempo o 'negro fugido' aterrava as populações de um modo fantástico. Dava-se caça ao escravo como aos animais, de espora e garrucha, mato adentro, saltando precipícios, atravessando rios a nado, galgando montanhas... Logo que o fato era denunciado - aqui-del-rei! - enchiam-se as florestas de tropel, saíam estafetas pelo sertão num clamor estranho, medindo pegadas, açulando cães, rompendo cafezais. Até fechavam-se as portas com medo...” (p. 39). Amaro pode ser o Bom Crioulo entre os marinheiros, mas nas ruas ele é a ameaça que ronda a cidade.

Do mesmo modo, sua homossexualidade não é vista como o "crime" que o narrador anuncia. Muito pelo contrário, resguardado por sua valentia, não se ouve mais do que rumores sobre sua relação com Aleixo. Há ainda a insinuação de que essa era uma prática comum nas embarcações da Marinha, tolerada e mesmo compartilhada pelos próprios oficiais. Bom Crioulo a confirma quando, atormentado pela ideia de fazer sexo com um homem, "revoltava-se contra semelhante imoralidade que os outros de categoria superior praticavam quase todas as noites ali mesmo sobre o convés..." (p. 51). É só do lado de fora que iremos ouvir a ofensa pronunciada com todas as palavras, por uma mulher que já fora sua amiga: "Grandessíssimo pederasta! Nunca supusera que uma paixão amorosa de homem a homem fosse tão duradoura, tão persistente! E logo um negro, Senhor Bom-Jesus, logo um crioulo imoral e repugnante daquele!” (p. 131).

A ambientação em um navio, espaço fechado e com regras próprias, muito embora cercado pela imensidão e pelos perigos do mar, também impõe alguns empecilhos, e algumas vantagens, à narrativa. A mais importante delas talvez seja a necessidade de concisão. Uma vez que não é objetivo do autor um romance introspectivo (no estilo de um Joseph Conrad, que também ambientou várias de suas narrativas em navios), não há muitos elementos para dispersar a narração. A agilidade utilizada na descrição do trabalho cotidiano e dos conflitos no navio vai ao limite quando os marinheiros têm de enfrentar uma tempestade, por exemplo. A cena é rápida, sem excessos, e dá a dimensão da movimentação à bordo e do pesadelo do lado de fora, "mar e céu confundindo-se na escuridão": 
Trilaram de novo os apitos num desespero de manobra açodada: avalanches de marinheiros precipitaram-se de um bordo e de outro, alando os cabos, atropelando-se em correrias de horda selvagem, batendo os pés, ao barulho dos moitões que chiavam como carro de bois na roça.

- Aguenta o leme! - avisava o oficial todo embuçado na sua capa impermeável.

O tempo escurecera completamente, e a ventania refrescando, esfuziava na mastreação de modo sinistro, com a força extraordinária de titãs invisíveis. Mar e céu confundiam-se na escuridão, formando um só conjunto negro em torno da corveta, abarcando-a em todos os sentidos, como se tudo ali dentro fosse desaparecer debaixo das águas e das nuvens... Passavam grandes ondas altaneiras, rugindo sob a quilha, dançando uma dança medonha e vertiginosa na proa, cada vez que o navio mergulhava o bojo com risco de abrir pelo meio... Chuva copiosíssima alagava o convés obrigando os marinheiros a se arregaçar, encharcando as pilhas de cabo, numa baldeação geral e inesperada.

A corveta ficara somente em gáveas e mezena, e corria, agora, sobre o mar, como se fosse um simples iatezinho de recreio, leve, enfunada, cavalgando as ondas - a bordas quase rentes com a água... (p. 56)

Mas mesmo quando a calmaria chega e o tédio se instala entre marinheiros e oficiais, bastam poucas palavras para o autor nos colocar diante da nova situação: "E o pano largo e frouxo a bater, a bater como uma coisa desesperada..." (p. 29).

O ritmo de narração imposto pelo navio não muda muito quando as personagens desembarcam. Ainda que o transcurso do tempo pareça mais lento - afinal, terra firme significa descanso para esses homens -, a agilidade já se infiltrou na trama. Do navio passamos então para a rua da Misericórdia, onde Amaro aluga um quarto, que abrigará Aleixo e suas fantasias de felicidade. Começa aí o que pode ser considerado um segundo momento do livro. No primeiro, fomos apresentados à vida dura dos trabalhadores em um navio - incluindo os castigos físicos aos marinheiros, que, 15 anos depois da publicação do livro, gerariam uma grande revolta, comandada pelo "almirante negro” João Cândido, que pôs fim à chibata (MoReL, 1979) - e à história de Bom Crioulo, de jovem escravo fugido a experiente marinheiro que se encanta por um garoto branco recém-embarcado.

No segundo momento, quase todo passado em terra firme, entra em cena outra personagem importante: D. Carolina, a portuguesa que aluga um quarto para Amaro, e para toda "gente que não se fizesse de muito honrada e de muito boa" (p. 72). Ex-prostituta, com uma história de vida cheia de altos e baixos, ela 
se vira, sem aceitar depender de homem nenhum: "Isso de homens não há que fiar: hoje com Deus, amanhã com o diabo" (p. 72). Se Amaro lutou para ser trabalhador livre, Carolina fugiu de outras escravidões, impostas a mulheres de qualquer cor, e aos 40 anos, madura e cansada, vê em Aleixo a beleza, a juventude e a paixão que já não possuía. Replicam-se aí os mesmos sentimentos, e as mesmas dúvidas, que já assaltaram antes Bom Crioulo: vergonha pelo inadequado da relação (a idade do garoto é vista inicialmente como um problema pelos dois), culpa (ele por estar apaixonado por um homem, ela por estar traindo um amigo), medo pela sensação de perda de controle da situação.

Nesse sentido, Aleixo deixa de ser apenas o garoto bonito que provoca paixões para significar tudo aquilo que um homem como Amaro (um corpo predestinado somente para o trabalho pesado) e uma mulher como Carolina (feita para dar gozo aos homens, não para receber prazer) jamais poderiam ter. Ambos são igualmente egoístas em relação ao jovem rapaz: Amaro considera-o seu, com exclusividade, Carolina acredita que o tem como um pássaro preso em uma gaiola. Como eles próprios, Aleixo é objetificado, visto como um corpo belo a lhes proporcionar deleite físico e estético. O narrador mesmo não se furta a descrevê-lo seguidamente como uma estátua grega. Mas, apesar disso, ainda é possível enxergar o garoto para além dessas três perspectivas - isso porque o narrador nos coloca diante dele em outras situações: seja contando suas histórias de filho de pescador, seja conversando com todos em meio à alegria, curioso e interessado pela vida, seja trabalhando, discreto e compenetrado.

Seu brutal assassinato (que poderia igualmente ter sido cometido por Carolina, já que ela mesma se diz capaz de matar) significa a destruição do objeto que não se pode ter, justamente porque não é isso que o garoto é. Aleixo, o aprendiz de marinheiro, cometeu o erro de se acreditar livre em um mundo cercado de escravidão, mas ele não era o garoto vazio que precisava de um adulto para existir. Seus amantes, esquecidos disso, passam de vítimas a algozes, perpetuando uma história de violência que prossegue até hoje, estampada diariamente nas manchetes dos jornais.

Aliás, talvez tenha sido exatamente das páginas dos jornais da época que Adolfo Caminha tirou a ideia para o seu romance. Em 1888 um jovem grumete pardo de 16 anos teria sido assassinado na rua da Misericórdia, o que foi 
fartamente noticiado pela imprensa carioca. Depois descobriu-se que era apenas uma farsa para a deserção do garoto. Outro caso, ocorrido em 1886 na Escola do Exército de Portugal, também bastante divulgado internacionalmente, foi o do assassinato envolvendo dois jovens cadetes que teriam uma relação homossexual, chegaram a morar juntos também - a causa aventada seria o ciúme. $O$ assassino, vindo de uma família de classe média (ao contrário da vítima, que era de uma família pobre), foi considerado mentalmente perturbado e encaminhado para um hospício, o que causou uma grande polêmica então, entre a sociedade e o meio científico. Após um recurso, ele foi condenado e preso.

Mas Caminha, republicano e abolicionista, também aproveitou sua experiência como oficial da Marinha para dar vida a suas personagens. Nascido no Ceará em 1867, ele se tornou órfão muito cedo, mudando-se para a casa de um tio no Rio de Janeiro e depois se matriculando na Escola Naval. Alguns anos depois retornou para Fortaleza, onde se apaixonou pela mulher de outro oficial, que largou o marido para viver com ele. O escândalo foi tão grande que ele teve de abandonar a Marinha e mudar-se com ela para o Rio de Janeiro. Lá, tornou-se funcionário público, complementava a renda escrevendo para jornais, teve duas filhas e morreu de tuberculose aos 29 anos de idade, em 1897, deixando, além de trabalhos inacabados, um livro de poesia, Voos incertos (1886); um de contos, Fudite e lágrimas de um crente (1887); um livro de viagem, No país dos ianques (1894); um de crítica, Cartas literárias (1895); e três romances, A normalista (1893), Bom Crioulo (1895) e Tentação (1896). Foram os dois primeiros romances que garantiram seu lugar na história da literatura brasileira; o restante de sua obra não é reeditado, nem lido, embora alguns títulos possam ser encontrados na Internet, como parte de projetos de digitalização de "clássicos" em língua portuguesa levados a cabo por diversas instituições.

Suas histórias são trágicas, e podiam ser consideradas escandalosas, envolvendo adultério, abuso sexual e traições, sempre com referências a lugares por onde passou e a pessoas que conheceu. Talvez também por isso Bom Crioulo tenha sido recebido tão friamente à época, sem resenhas ou comentários nos jornais, afora duas críticas bastante hostis. Uma, de Valentim Magalhães, nome importante na época, que pouco tempo depois estaria entre os fundadores da Academia Brasileira de Letras, acusava o autor de ser "um inconsciente, por obcecação literária ou perversão moral. Só assim se pode explicar o fato de haver ele achado literário tal assunto, de ter julgado que a 
história dos vícios bestiais de um marinheiro negro e boçal podia ser literariamente interessante". E outra, sem assinatura, mas que se creditava a José Veríssimo, o mais influente crítico literário do período - e, aliás, outro sócio-fundador da Academia -, que perguntava "como quer o sr. Adolfo Caminha que seja respeitado e estimado um homem que, sem utilidade alguma social, passou longos dias ocupado em analisar e discutir a psicologia improvável de nauseantes crimes contra a natureza e tenta depois com isso despertar em nós o arrepio da curiosidade impura e mórbida?”.

O romance não chegou a ser proibido, tampouco a Marinha moveu qualquer processo contra o autor na época, apesar do óbvio incômodo que a obra deve ter causado. Mas uma segunda edição só foi publicada décadas depois do seu lançamento, no final dos anos 1930. Daí sim, em plena ditadura Vargas, o livro chegou a ser apreendido, por solicitação da Marinha, acusado de propaganda comunista. Após uma apelação da família, foi liberado. O que não quer dizer que tenha passado a frequentar as bibliotecas. A censura ao livro, considerado obsceno, se deu, como ressaltaram vários críticos mais tarde, pelo silenciamento - ou se ignorava completamente o livro, ou ele era descartado sob a alegação ligeira de falta de qualidade estética. E o principal mercado para obras de sua época, a adoção como leitura obrigatória em instituições de ensino, estava fechado. Que escola, que professor adotaria em sala de aula um romance que unia a denúncia da exploração do trabalho a uma temática homoafetiva? Só a partir dos anos 1980 o livro passará a ter edições mais frequentes e cuidadas. ${ }^{5}$

Bom Crioulo está inscrito na história literária brasileira (como se vê, não sem esforço) como um romance naturalista. Caminha é, ao lado de Júlio Ribeiro e logo após Aluísio Azevedo, sempre citado entre os principais expoentes do naturalismo no país. De fato, ele dialoga com as teorias científicas da época, mas nem sempre as segue por completo. Deve, especialmente, a algumas das formulações de Emile Zola no ensaio "O romance experimental”, de 1880. Seguindo o método proposto por Claude Bernard para as ciências médicas em Introduction à l'étude de la médecine expérimentale, de 1865, Zola começa por diferenciar o observador, que "constata pura e simplesmente os fenômenos que tem diante dos olhos", do experimentador, aquele que "instituiu a experiência

\footnotetext{
4 As informações sobre a recepção da obra de Adolfo Caminha, bem como detalhes sobre os casos de assassinato divulgados nos jornais da época, podem ser encontradas em Howes (2005, p. 171-190).

5 Sobre a crítica posterior ao livro, ver Trevisan (2009).
} 
de maneira que, na ordem lógica das previsões, ela forneça um resultado que sirva de controle da hipótese ou ideia preconcebida”. A experiência, assim, não passa de uma "observação provocada". Dentro desta perspectiva, o romance experimental não deveria se preocupar com o porquê das coisas, mas sim com o como (ZolA, 1982, p. 30).

Para Zola, enquanto a observação "mostra”, a experiência "instrui”. Por isso a necessidade de reunir os dois procedimentos num só processo. Assim, o método experimental se daria a partir da constatação dos fatos e da observação do fenômeno, seguidos pelo surgimento da ideia. Até esse momento, é o observador quem deve atuar. Só então é preciso que o experimentador passe a agir. É ele quem vai, partindo de uma interpretação do fenômeno, instituir a experiência "de maneira que, na ordem lógica das previsões, ela forneça um resultado que sirva de controle da hipótese ou ideia preconcebida”. Logo que o resultado se manifesta, o experimentador "encontra-se em face de uma verdadeira observação, que ele provocou e que, como toda observação, deve ser constatada sem ideia preconcebida" (ZoLA, 1982, p. 30).

Traduzindo isso para a literatura, e repetindo a ideia de que um romancista deve ser feito de um observador e um experimentador, Zola explica que o observador deve apresentar os fatos, estabelecendo "o terreno sólido no qual as personagens vão andar e os fenômenos se desenvolver”. Já o experimentador se encarregaria da experiência, de fazer "as personagens evoluírem numa história particular, para mostrar que a sucessão dos fatos será tal qual a exige o determinismo dos fenômenos estudados”. Essa seria, em suma, a fórmula para o romance experimental, lembrando que o romancista, durante todo o processo, deve manter-se na postura de um pesquisador - objetivo e impessoal (ZolA, 1982, p. 31).

A visão positivista que Zola expressa não encontra mais guarida nem nas ciências naturais. Sua aplicação ao fazer literário parece involuntariamente cômica. É importante perceber, porém, que o naturalismo desempenhou um papel fundamental na desorganização das hierarquias de temas e assuntos, mostrando que há, sim, interesse, complexidade e humanidade na vida das pessoas pobres, comuns, desprovidas de poder. Mas mesmo Zola, que nos legou uma legião de operários em greve, prostitutas, feirantes, pequenos lojistas, não pôs em cena uma personagem como Bom Crioulo.

Como observador, Adolfo Caminha registra a movimentação do navio, o leve bater das velas, a superfície imóvel do oceano, a nostalgia da paisagem que 
ficou para trás, e vai nos introduzindo, ao mesmo tempo, aos homens que habitam esse mundo, ex-escravos, filhos de pescadores, gente pobre que encontrava na Marinha um jeito de sobreviver, além dos oficiais, alguns desprezados em sua petulância, outros respeitados e admirados. A esse observador não passam despercebidos os menores detalhes: o "belo cronômetro de ouro comprado em Toulon" (p. 26) e ostentado por um tenente; a musculatura perfeita de Amaro, "emprestando-lhe movimentos extraordinários, invencíveis mesmo, de um acrobatismo imprevisto e raro" (p. 36); ou mesmo "um tímido murmúrio nas fileiras da marinhagem, assim como o vago estremecimento que assalta os espectadores de um teatro nas mutações do cenário" (p. 35). Logo em seguida, o observador indica o fenômeno que será analisado - a paixão.

Sobre esse fenômeno passa a atuar o experimentador, que colocará as personagens "à prova" conduzindo-as de acordo com hipóteses já formuladas pelos discursos científicos da época, em especial a medicina e a psicologia. Aqui, Caminha ecoa os temas caros ao naturalismo: a força avassaladora dos impulsos animais, o peso da hereditariedade, a tendência à degeneração. Bom Crioulo é um homem respeitado por sua força, uma força que só o torna perigoso quando sob o efeito do álcool. No mais, ele é "admiravelmente manso" (p. 37). Nem o trabalho pesado, nem os mais cruéis castigos o desanimam. Amigo de todos os tripulantes, subserviente e trabalhador, Bom Crioulo torna-se "esquecido e indiferente" (p. 46) depois de conhecer o jovem aprendiz. E essas são apenas as primeiras transformações que se dão em sua personalidade. Aos poucos, empurrado pelas circunstâncias e pela natureza que "pode mais que a vontade humana" (p. 67) - Bom Crioulo entrega-se à luxúria, para de trabalhar e começa a exibir um caráter violento, já sem "forças para resistir aos impulsos do sangue" (p. 51), até que, "tresvariado, como se de repente lhe houvesse fugido a luz dos olhos e a razão do cérebro" (p. 154), mata.

Mas, essa, como já vimos, não é a única história, talvez nem mesmo a mais importante delas. Entremeadas a um roteiro naturalista - eivado de simplificações, de estereótipos -, vão aparecendo, extremamente vivas, outras facetas das personagens, e outras facetas de um discurso que se quer correto e integral, mas que, na verdade, fala da perspectiva de uma classe. Como o discurso do valor moral do trabalho, por exemplo, que se junta, quase invariavelmente, a um discurso de controle dos corpos. Ao dar vazão a outras possibilidades de apreensão do mundo social e a outros modos de viver a 
sexualidade, Adolfo Caminha instaura a ambiguidade em sua narrativa. Graças a essa ambiguidade, Bom Crioulo não é apenas um documento de época ou uma correta aplicação, no Brasil, das teorias do naturalismo francês. É um romance que, sem se querer "atemporal" (qualidade que, a rigor, só seria conquistada por uma obra que negasse aquilo que possui de mais valioso, seu caráter humano), é capaz de desafiar seus leitores mais de um século depois de ter sido escrito. E que, por isso mesmo, deve ser lido não com a condescendência destinada aos velhos textos do passado, nem com o enfado ao qual se relegam as tarefas escolares, mas com o rigor crítico e o interesse que merecem as obras que ainda falam a nós.

\section{Referências}

Caminha, Adolfo. Bom Crioulo. São Paulo: Hedra, 2009.

DALCASTAgnè, Regina. Literatura brasileira contemporânea: um território contestado. Rio de Janeiro: Editora da UERJ; Vinhedo: Horizonte, 2012.

FERRÉz. Ninguém é inocente em São Paulo. Rio de Janeiro: Objetiva, 2006.

Howes, Robert. Raça e sexualidade transgressiva em Bom Crioulo de Adolfo Caminha. Graphos, João Pessoa, v. 7, n. 2/1, p. 171-190, 2005.

MoREL, Edmar. A Revolta da Chibata: subsídios para a história da sublevação da Esquadra pelo marinheiro João Cândido em 1910. 3. ed. Rio de Janeiro: Graal, 1979.

Trevisan, João Silvério. Introdução. In: CAminha, Adolfo. Bom Crioulo. São Paulo: Hedra, 2009.

Young, Iris Marion. Inclusion and democracy. Oxford: Oxford University Press, 2000.

ZolA, Emile. O romance experimental e O naturalismo no teatro. São Paulo: Perspectiva, 1982.

Recebido em 12 de fevereiro de 2017.

Aprovado em 3 de março de 2017.

\section{Resumo/Abstract/Resumen}

\section{Retrato sem parede: o Bom Crioulo, de Adolfo Caminha}

Regina Dalcastagnè

O artigo pretende discutir a importância da releitura do romance Bom Crioulo, de Adolfo Caminha, no contexto atual. Lançado em 1895, para escândalo da sociedade da época, ele continua, de algum modo, sendo uma perturbação no cenário cultural brasileiro. Reivindicado como o primeiro romance nacional a trazer a público um protagonista gay, Bom Crioulo chama atenção ainda para uma série de outras ausências em nossa 
literatura - não apenas a do século xix, mas também a de hoje, que, de um modo geral, não dá guarida para personagens como Amaro.

Palavras-chave: classe, raça, homossexualidade, século 19, Adolfo Caminha.

\section{A portrait without a wall: the novel Bom Crioulo, by Adolfo Caminha}

\section{Regina Dalcastagnè}

This paper aims to discuss the importance of reading the novel Bom Crioulo, by Adolfo Caminha, at the present time. Published in 1895 , it was a scandal for the society of the time and it somehow continues to be a polemical work in the Brazilian cultural scenario. Recently considered to be the first Brazilian novel to have a gay protagonist, Bom Crioulo calls our attention to a series of other absences in our literature - not only the literature of the nineteenth century, but also the one from our days that, generally speaking, does not provide much opportunity for characters such as Amaro.

Keywords: class, race, homosexuality, $19^{\text {th }}$ Century, Adolfo Caminha.

\section{Retrato sin pared: Bom Crioulo, de Adolfo Caminha}

Regina Dalcastagnè

El artículo aborda la importancia de la relectura de la novela Bom Crioulo, de Adolfo Caminha, en el contexto actual. Lanzado en 1895, para escándalo de la sociedad de la época, sigue siendo, de alguna manera, una perturbación en la escena cultural brasileña. Reclamado hoy como la primera novela nacional con un protagonista homosexual, Bom Crioulo llama la atención también hacia una serie de otras ausencias en nuestra literatura - no solo la del siglo xix, sino también la de hoy en día - que, en general, no da cobijo a personajes como Amaro.

Palabras clave: clase, raza, homosexualidad, siglo 19, Adolfo Caminha. 